Edwards, P. R. \& Boycott, J. A. (1955). J. gen. Microbiol. 13, 569-571

\title{
Four New Diphasic Members of the Arizona Group of Bacteria found in Reptiles
}

\author{
By P. R. EDWARDS AND J. A. BOYCOTT \\ Communicable Disease Center, Chamblee, Georgia, U.S.A., and the Public \\ Health Laboratory, Taunton, Somerset
}

SUMMARY: Four hitherto undescribed diphasic members of the Arizona group of bacteria were identified in reptilian faeces. These organisms appear to occur frequently in healthy Constrictor constrictor.

Not many diphasic members of the Arizona group of bacteria have been recognized. This paper describes four new species found in the excreta of apparently healthy reptiles imported into England.

\section{METHODS}

All the organisms were isolated on deoxycholate citrate agar or Wilson and Blair agar, either inoculated directly or after enrichment in selenite broth. The methods used for biochemical and serological examination were those employed by Edwards, West \& Bruner (1947) in whose paper the type cultures mentioned are described.

\section{DESCRIPTIONS OF ORGANISMS}

The organisms were motile rods with the usual appearances and cultural characters of enteric bacteria. All produced hydrogen sulphide, failed to form indole, were methyl red-positive and Voges-Proskauer-negative, utilized citrate and D-tartrate and did not hydrolyse urea. All fermented glucose, arabinose, xylose, rhamnose, maltose, trehalose, mannitol and sorbitol rapidly with the production of gas. Sucrose, adonitol, dulcitol, inositol and salicin were not fermented.

Organism 3829/53. From a tortoise (Testudo graeca) imported from Casablanca, Morocco: Salmonella abortus-bovis was found in the same specimen. This strain liquefied gelatin in 13 days and fermented lactose within $24 \mathrm{hr}$. It was agglutinated to titre by Arizona $O$ group 9 antiserum and in adsorption tests removed all agglutinins from this serum. Of the $\mathrm{H}$ antigens phase $\mathbf{1}$ was identical with phase 1 of Pc. 195 (Arizona H 21) and phase 2 with phase 1 of Pc. 196 (Arizona H 26) (Edwards et al. 1947). The antigenic formula is therefore Arizona $9: 21-26$. Of these antigens only $\mathrm{H} \mathrm{21}$, which is closely related to phase 2 of $\boldsymbol{S}$. chittagong $\left(\mathrm{z}_{35}\right)$, is related to recognized Salmonella antigens.

Organism 3834/53. From a snake (Constrictor constrictor) imported from Mexico. The same specimen yielded the diphasic Arizona type 29:31-33. $3834 / 53$ liquefied gelatin in 18 days and fermented lactose within $24 \mathrm{hr}$. The $O$ antigens were identical with those of 557/52 (Arizona O 29) (Edwards, 
Kauffman \& Fain, 1953). Phase 1 of the $\mathbf{H}$ antigens was closely related to phase 1 of Salmonella poona and identical with phase 1 of Cal. 1141 (Arizona H 31). Phase 2 removed all $\mathrm{H}$ agglutinins from $S$. cholerae-suis phase 1 serum and from Arizona $\mathrm{H} 32$ serum. (The relations between this antigen and the Salmonella c antigen were described by Edwards, Kauffman \& van Oye, 1952.) For the antigens found in both phases to be closely related to antigens found only in phase $\mathbf{1}$ in Salmonella is not uncommon in diphasic Arizona strains. The antigenic formula is $29: 31-32$.

Organism 599/54. From Constrictor constrictor from Mexico; this also harboured Arizona $29: 31-33$. Gelatin was liquefied in 15 days and lactose fermented after 4 days. This belonged to Arizona $O$ group 16, the somatic antigens of which are identical with those of Salmonella inverness. When first examined this culture was poorly motile and was not flocculated by any $\mathbf{H}$ sera of the Arizona or Salmonella groups. Many passages through semi-solid medium were needed to induce motility, but ultimately a serum was produced which agglutinated the culture rapidly, completely and in high dilution. The organisms were cultivated in semi-solid medium to which $599 / 54$ serum had been added in the hope of isolating a second phase but no migration occurred. The serum was then tested with all the $\mathbf{H}$ antigens known to occur in diphasic Arizona strains. Only $\mathbf{H}$ antigen 23 was flocculated and the reaction did not extend beyond a dilution of $1 / 1000$. The $O$ agglutinins and agglutinins for $\mathrm{H} 23$ were removed from the 599/54 serum by adsorption with heated cells of the homologous culture and with phase 2 of Pc. 195 (Arizona H 23) (Edwards, et al. 1947). When this absorbed serum was added to semi-solid medium the culture spread rapidly through its substance. From the spreading growth organisms were obtained which possessed $\mathbf{H}$ antigens indistinguishable from those of Pc. 195, phase 2 (Arizona $\mathbf{H} 23$ ). These antigens are related to but not identical with those of phase 1 of $S$. uganda $\left(1, \mathrm{z}_{13}\right)$. Since $\mathrm{H}$ antigen 23 has usually been found in combination with antigens which have been placed in the phase 2 of Arizona types, H 23 was designated as phase 1 in 599/54. The hitherto undescribed phase in which the culture occurred originally was designated phase 2 and given the symbol $\mathbf{H}$ 34. The formula is therefore Arizona 16:23-34. An identical strain was isolated from another Constrictor constrictor imported at the same time, and shortly afterwards a third strain was received from the Michigan Department of Health. This had been isolated by Miss Elizabeth Cope at the autopsy of a snake of the same species at the Detroit zoo.

Organism 4601/54. From Constrictor constrictor from Mexico: Arizona 9 : 24-31, Salmonella enteritidis (jena) and Salmonella n.sp. 13, 22: $\mathrm{z}_{29}$ were found in the same specimen. This organism liquefied gelatin in 20 days and fermented lactose within $24 \mathrm{hr}$. The $\mathrm{O}$ antigens were not related to any of the known $\mathrm{O}$ antigens of the Arizona or Salmonella groups. Alcohol-treated suspensions of $4601 / 54$ were not agglutinated by Arizona or salmonella $\mathrm{O}$ sera at a dilution of 1 in 50. Likewise an $O$ serum prepared from 4601/54 which had a homologous titre of $1 / 6400$ failed to agglutinate representatives of the various Arizona and Salmonella groups at a dilution of 1 in 50. The symbol 30 was 
assigned to this new $\mathbf{O}$ group. Of the $\mathrm{H}$ antigens phase 1 was agglutinated to titre by Arizona $\mathbf{H} 23$ serum and in absorption tests reduced the titre from 1 in 5000 to 1 in 200. Phase 2 was agglutinated to titre by and removed all agglutinins from Arizona $\mathbf{H} 31$ serum. The antigenic formula is Arizona 30 : 23-31.

\section{COMMENT}

For several years after they were first recognized diphasic members of the Arizona group were rarely found. There were two reasons for this. The majority of strains ferment lactose rapidly and are therefore discarded. The realization that the fermentation of lactose is not an absolute screening test per se will tend to correct this. The second reason is that so far reptiles have been the commonest source of these diphasic organisms, providing 19 out of a total 30 isolations. It is noteworthy that we found diphasic Arizona strains in the excreta of 8 out of 9 Constrictor constrictor examined. Besides those described we found the following: $9: 24-31$ (once), $16: 23-25$ (once), $29: 31-33$ (five times). Three snakes harboured two strains simultaneously. No monophasic Arizona strains were found. In contrast to this 311 examinations of the faeces from 45 specimens of Testudo graeca yielded only 3829/53 and 4 monophasic strains.

These findings add support to the supposition that the diphasic types of Arizona organisms tend to be less pathogenic than the more numerous monophasic types. On ten out of the nineteen occasions on which they have been found in reptiles they have been found at autopsy but their part in causing death is unknown. They have been isolated from the internal organs of turkeys in three flocks and in these instances no other cause of death could be found. Once they were found in the organs of foetuses delivered during an outbreak of abortion among ewes. In man they have been found twice: in a healthy food handler and in the faeces of a man with fever and diarrhoea.

\section{REFERENCES}

Edwards, P. R., Kauffman, F. \& van Oye, E. (1952). A new diphasic Arizona type. Acta path. microbiol. scand. 31, 5.

Edwards, P. R., Kauffman, F. \& Fain, A. (1953). Two new diphasic Arizona types. Acta path. microbiol. scand. 31, 191.

Edwards, P. R., West, M. G. \& Bruner, D. W. (1947). Arizona group of paracolon bacteria. Bull. Ky. agric. Exp. Sta. no. 499.

(Received 12 July 1955) 